\title{
Avaliação da influência do aquecimento da liga de alumínio AA5083 na corrosão em ambiente salino
}

\section{Evaluation of the influence of heating on aluminum alloy AA5083 in corrosion in saline medium}

Marcos Paulo Souza Ribeiro*, Ana Beatriz Ramos Moreira Abrahão, Leide Lili Gonçalves Silva, Alexandre Sartori, Rafael Oliveira Santos, Isabela Luiza Rodrigues Cintra

\section{RESUMO}

A liga de alumínio AA5083 é bastante utilizada na fabricação de tanques rodoviários, armazenamento de produtos químicos, silos para estocagem de grãos e tem importantes aplicações marítimas. Sabe-se que a resistência à corrosão de ligas com mais de 3\% de magnésio é bastante afetada quando exposta a temperaturas elevadas por tempo prolongado. O monitoramento da corrosão consiste na utilização de técnicas que permitam avaliar os processos de corrosão que possam afetar a integridade do material e prever medidas corretivas que assegurem a vida longa para equipamentos e instalações. Portanto, este trabalho visa a estudar o efeito do pré-aquecimento da liga de alumínio AA5083 em relação à resistência à corrosão em meio salino. Para esse fim, os seguintes ensaios foram utilizados: método potenciodinâmico, ensaio de imersão e câmara salina. Após esses ensaios, as amostras foram caracterizadas por meio das análises macroscópica, microscópica, microdureza Vickers e medidas de perda de massa. Os resultados evidenciaram que o aquecimento da liga estudada diminui sua resistência à corrosão em meio salino e apresenta corrosão por pites e intergranular mais acentuada.

Palavras-chave: Sensitização, Corrosão, Alumínio, 5083, Potenciodinâmico.

\begin{abstract}
The AA508 aluminum alloy is widely used in the manufacture of road tanks, chemical storage, silos for grain storage and large marine applications. It is known that the corrosion resistance of alloys with more than $3 \%$ of magnesium is very high when exposed to higher temperatures for a long time. Corrosion monitoring consists in using techniques that allows to evaluate the corrosion process that can affect the integrity of material and also to provide corrective measures that ensure a long life of equipment and facilities. So, the purpose of this work is to study the effect of heating the AA5083aluminum alloy on corrosion resistance in saline medium. For this purpose, the following methods are performed: potenciodinamic, immersion and saline chamber. After these, the samples were characterized by macroscopic and microscopic analyses, Vickers microhardness and mass loss measurements. The results evidenced that the heating of studied alloy decreased its corrosion resistance in saline environment and showed pitting and intergranular corrosion, more accentuated.
\end{abstract}

Keywords: Sensitization, Corrosion, Aluminum, 5083, Potenciodynamic. 


\section{INTRODUÇÃO}

O alumínio, apesar de ser o terceiro elemento mais abundante na crosta terrestre, é o metal mais jovem usado em escala industrial (ABAL, 2003). Esse metal apresenta autoproteção natural que só é destruída por uma condição agressiva ou por determinada substância que dissipe sua película de óxido de alumínio $\left(\mathrm{Al}_{2} \mathrm{O}_{3}\right)$ de proteção. Essa propriedade facilita a conservação de produtos como portas e revestimentos usados na construção civil, bem como em equipamentos, partes e estruturas de veículos de qualquer porte, conforme a Associação Brasileira do Alumínio ${ }^{1}$.

As ligas de alumínio foram divididas em dois grupos, das ligas trabalhadas e o das ligas forjadas, foram agrupadas em famílias ou séries e cada liga dentro de uma mesma série é identificada por um sistema de quatro dígitos ${ }^{2}$.

Para a série $1 \mathrm{xxx}$, o primeiro dígito designa o alumínio comercialmente puro, que indica aproximadamente $99 \%$ de pureza. Para as ligas $2 \mathrm{xxx}$ a $8 \mathrm{xxx}$, o primeiro dígito designa a série à qual pertence a liga e seu principal elemento, no qual as ligas da série $2 \mathrm{xxx}$, 6xxx e $7 \mathrm{xxx}$ são utilizadas para trabalhos mecânicos e tratamentos térmicos. As ligas da série 1xxx, 3xxx e 5xxx são ligas de trabalhos mecânicos sem tratamentos térmicos ${ }^{3}$.

O alumínio 5083 contém 3 a 5\% de cromo e manganês, apresentando as melhores propriedades da série $5 \mathrm{xxx}$, como boa soldabilidade e alta resistência; sobretudo em atmosfera marítima, seu uso é muito comum na indústria naval. Nas ligas comerciais, além do manganês, estão presentes outros elementos de liga em menor quantidade que contribuem para a formação da fase $\beta$-Al6 (Fe, Mn) 2,4. Na Tabela 1 encontra-se a composição química da liga 5083.

As ligas Al-Mg são muito resistentes à corrosão e à água do mar, sua resistência é aumentada segundo o grau de endurecimento a frio e sua aplicação se estende a todos os casos nos quais se necessita dessa propriedade específica, como, por exemplo, na construção naval $^{6}$. A velocidade de corrosão do alumínio na atmosfera é relativamente baixa e tende a diminuir ao longo do tempo de exposição, com o acúmulo na superfície do metal do produto da corrosão na camada da passivação. A liga AA5083 com 3\% de magnésio pode se tornar susceptível ao ataque intergranular e à corrosão sobtensão quando exposta a temperaturas na faixa entre 50 e $225^{\circ} \mathrm{C}^{7}$.

Segundo Sartori e Silva ${ }^{8}$, as ligas contendo mais magnésio em solução sólida do que o equilíbrio permite tendem a precipitar o excesso na forma de um componente denominado $\beta\left(\mathrm{Mg}_{2} \mathrm{Al}_{3}\right)$ que, quando precipitado no metal, causa um efeito considerável na liga alumínio-magnésio. Esse precipitado é altamente anódico, fazendo com que a precipitação diminua fortemente sua resistência à corrosão, tendendo a gerar corrosão intergranular, sobtensão ou corrosão por esfoliação.

A corrosão intergranular ocorre nos contornos de grãos resultando em seu desprendimento. Quando aquecidas durante determinado tempo, algumas ligas tornam-se susceptíveis a esse tipo de ataque. Essa corrosão tem mecanismo eletroquímico, no qual alguns elementos da liga, no momento da difusão, deslocam-se até o contorno de grão, a fim de formar precipitado, o que resulta no empobrecimento da estrutura, conforme Sartori e Veiga ${ }^{9}$ e Ramanathan ${ }^{10}$. Ligas de alumínio-magnésio com mais de 3\% de magnésio em sua composição, quando expostas a determinadas temperaturas durante determinado período de tempo, apresentam um precipitado de $\mathrm{Mg}_{2} \mathrm{Al}_{3}$ nos contornos de grão. Esses precipitados são menos nobres que a matriz do grão, gerando, assim, a propagação da corrosão intergranular ${ }^{11}$.

O monitoramento da corrosão consiste na utilização de técnicas que permitam avaliar os processos de corrosão que possam afetar a integridade do material. $\mathrm{O}$ monitoramento também pode ser realizado por meio de ações para prever medidas corretivas que assegurem vida longa para equipamentos e instalações. O método potenciodinâmico é amplamente utilizado no monitoramento da corrosão, no qual são obtidas as curvas de polarização do material. Adicionalmente, esse método é baseado nos fenômenos de polarização e passivação, que assumem importante papel na cinética dos processos de corrosão eletroquímica, na vida útil do material e na determinação da corrente de corrosão $0^{11-13}$.

O potencial de corrosão pode ser determinado por meio das curvas de polarização do material a ser estudado em contato com um meio corrosivo para avaliar o potencial de corrosão e determinar sua corrente de corrosão ${ }^{11,14}$. Nesse contexto, a proposta deste trabalho é analisar o efeito da temperatura na resistência à corrosão da liga de alumínio AA 5083 em ambiente salino.

\section{MATERIAIS E MÉTODOS}

\section{Materiais}

A liga AA5083 é um material não tratável termicamente que tem média resistência mecânica e é conhecida por apresentar excelente resistência à corrosão. No entanto, a liga pode se tornar susceptível ao ataque intergranular e à corrosão sobtensão quando exposta a temperaturas na faixa entre 50 e $200{ }^{\circ} \mathrm{C}$ por períodos suficientemente longos. Os corpos de provas da liga de alumínio

Tabela 1: Composição química da liga de alumínio AA 5083.

\begin{tabular}{c|c|c|c|c|c|c|c|c|c|c|c|}
\hline$\%$ & Si & Fe & Cu & Mn & Mg & Cr & Zn & Ti & Outros \\
\hline Min & & & & 0,40 & 4,00 & 0,05 & & & 0,15 \\
\hline Máx & 0,40 & 0,40 & 0,100 & 1,00 & 4,90 & 0,25 & 0,25 & 0,15 & 0,15 \\
\hline
\end{tabular}

Fonte: Martins ${ }^{5}$. 
AA 5083 foram confeccionados em um total de quatro amostras com diâmetro de $14,9 \mathrm{~mm}$ e espessura de $4 \mathrm{~mm}$, como mostrado na Fig. 1.

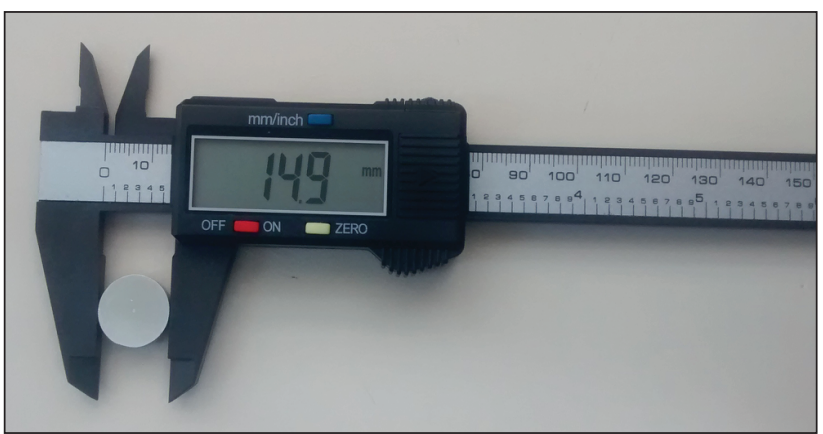

Figura 1: Corpo de prova para realização do ensaio potenciodinâmico AA 5083.

\section{Processo de Aquecimento}

Depois de confeccionadas, as amostras foram colocadas em um forno marca Grion e submetidas à atmosfera de oxigênio em temperatura de $180^{\circ} \mathrm{C}$ durante $72 \mathrm{~h}$.

\section{Ensaio Potenciodinâmico}

Para realização do ensaio potenciodinâmico, as amostras foram lixadas com lixa de granulometria de 180 a 2.000 e polidas com pasta de diamante de $3 \mu \mathrm{m}$. A análise eletroquímica foi realizada por meio de dois métodos: potencial de circuito aberto (open circuit potential - OCP) e curvas de polarização. Os ensaios foram realizados no equipamento da marca Autolab, modelo PGSTAT 302 N. A amostra foi inserida na célula eletrolítica contendo três eletrodos, sendo que o eletrodo de trabalho consistiu de amostras de cobre e seus diferentes revestimentos, com a área exposta de $0,8 \mathrm{~cm}^{2}$, eletrodo de referência $(\mathrm{Ag} / \mathrm{AgCl})$ e dois contraeletrodos de platina.

Para realização dos ensaios, utilizou-se solução aerada de alta condutividade de $\mathrm{NaCl} 3,5 \%$ (p/p) com (pH 6,2) em temperatura ambiente. Todas as amostras permaneceram imersas em solução por aproximadamente $22 \mathrm{~h}$ para estabilização do potencial e, após esse período, realizou-se a medida de $O C P$ no período de 2 h. Logo após, obtiveram-se as curvas de polarização para se determinar a densidade de corrente de corrosão nas quais foi aplicada uma faixa de potencial de $-1,0$ até $-0,5 \mathrm{~V}$, com velocidade de varredura de $0,33 \mathrm{mV} / \mathrm{s}$.

\section{Ensaio de Imersão das Amostras em Água do Mar}

Foram confeccionadas, ao todo, quatro amostras de ligas de alumínio AA 5083, sendo as amostras: duas aquecidas e duas nas condições de como recebida. As dimensões das amostras lixadas e as medidas de suas massas iniciais para os testes de imersão em água salina são mostradas na Tabela 2.

Para realização do teste de imersão, as amostras foram colocadas em béqueres de $50 \mathrm{~mL}$ com $30 \mathrm{~mL}$ de água do mar da Praia do Tenório, Ubatuba, estado de São Paulo.
Tabela 2: Valores das áreas e massas das amostras.

\begin{tabular}{c|c|c|c|}
$\begin{array}{c}\text { Dias de } \\
\text { imersão }\end{array}$ & Amostras & $\begin{array}{c}\text { Área } \\
\left(\mathbf{m m}^{2}\right)\end{array}$ & $\begin{array}{c}\text { Massa iniciais } \\
\text { das amostras (g) }\end{array}$ \\
\hline \multirow{2}{*}{120} & Padrão $(\mathrm{n} / \mathrm{s}) 2$ & 404,95 & 1,4681 \\
& Aquecida (s) 2 & 407,89 & 1,1080 \\
\hline
\end{tabular}

\section{Ensaio de Microdureza Vickers}

O ensaio de microdureza Vickers fornece a escala de dureza contínua e é aplicável a uma gama de materiais e microestruturas. A impressão do endentador de diamante é extremamente pequena e com aplicações de cargas de 1 a 1.000 g. As amostras foram limpas com acetona e álcool na superfície para deixá-las isentas de impurezas e óxidos. Todos os testes são realizados na escala de 0,1 Kgf, aplicando-se a carga na superfície da amostra por $15 \mathrm{~s}$, segundo a norma ASTM E92, de 1997.

\section{Microscopia Óptica}

A análise foi executada por microscopia óptica utilizando-se o estereoscópio da marca Olympus SZ2-ET com aumento de 6,7 a 45X e do microscópio óptico da marca Zeiss modelo Vert.A1.

\section{Microscopia de Varredura}

Essa etapa teve como objetivo mostrar o efeito da corrosão após a realização do teste potenciodinâmico, mostrando, assim, o efeito e o tipo de corrosão nas amostras da liga AA 5083 padrão tratadas termicamente. Para obtenção das imagens, utilizou-se o microscópio de varredura eletrônica da marca Zeiss, modelo LEO 1450VP.

\section{RESULTADOS E DISCUSSÕES}

\section{OCP e Curvas de Polarização Potenciodinâmica}

Com os resultados do teste de $O C P$, fizeram-se as comparações da liga AA5083 comum e aquecida, como mostrado na Fig. 2, que apresenta as curvas dos potenciais em função do tempo.

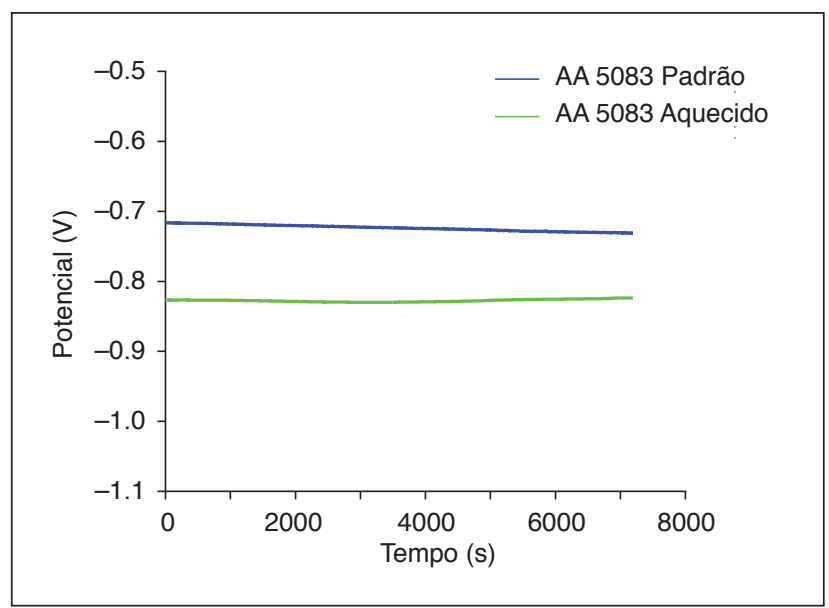

Figura 2: Curvas de OCP. 
Após o tempo de imersão, observou-se que o comportamento das duas curvas foi similar, ou seja, ocorreu leve diminuição do potencial em função do tempo até alcançar a estabilização do potencial. A liga AA5083 padrão apresentou potencial de estabilização em torno de $-0,72 \mathrm{~V}$, enquanto a liga AA5083 aquecida apresentou comportamento levemente menos nobre, com potencial de estabilização de aproximadamente $-0,82 \mathrm{~V}$.

Na Fig. 3 são apresentadas as curvas de polarização das amostras de ligas AA5083 padrão e aquecida. No geral, para as duas curvas, ocorre diminuição da densidade de corrente de corrosão com aumento do potencial aplicado (a partir de -1,0 V) até atingir o potencial de corrosão. Como observado pela convergência entre as curvas catódica (inferior) e anódica (superior), o valor de densidade de corrente aumenta em função do aumento de potencial aplicado.

A liga AA5083 aquecida apresentou densidade de corrente em torno de $8,7 \times 10^{-8} \mathrm{~A} / \mathrm{cm}^{2}$ e potencial de corrosão de aproximadamente $-0,84 \mathrm{~V}$, aproximadamente cinco vezes maior que a densidade de corrente de corrosão da liga padrão $\left(1,6 \times 10^{-8} \mathrm{~A} / \mathrm{cm}^{2}\right)$ com potencial de $-0,77 \mathrm{~V}$. Esse aumento na densidade de corrente de corrosão corresponde a uma pequena diminuição da resistência à corrosão após o aquecimento da liga.

Na Fig. 3, as curvas de polarização mostraram, também, a presença de uma região de densidade de corrente constante atribuída à formação de uma camada passiva. A região passiva da liga AA5083 aquecida inicia-se em - $0,84 \mathrm{~V}$ até $-0,70 \mathrm{~V}$; após esse valor, a camada de óxido é rompida. Essa região corresponde à densidade de corrente de $2,4 \times 10-6 \mathrm{~A} / \mathrm{cm}^{2}$, maior que a região passiva da liga padrão de $-0,77 \mathrm{~V}$ a $-0,66 \mathrm{~V}$, aproximadamente, sugerindo a formação de uma camada passiva mais espessa do que a da liga padrão. A presença da camada passiva nas curvas de polarização obtidas em solução de $\mathrm{NaCl}$ 0,6M (3,5\% pp) também foi observada por Birbilis e Buchheit ${ }^{15}$, no estudo das características eletroquímicas de fases intermetálicas nas ligas de alumínio.

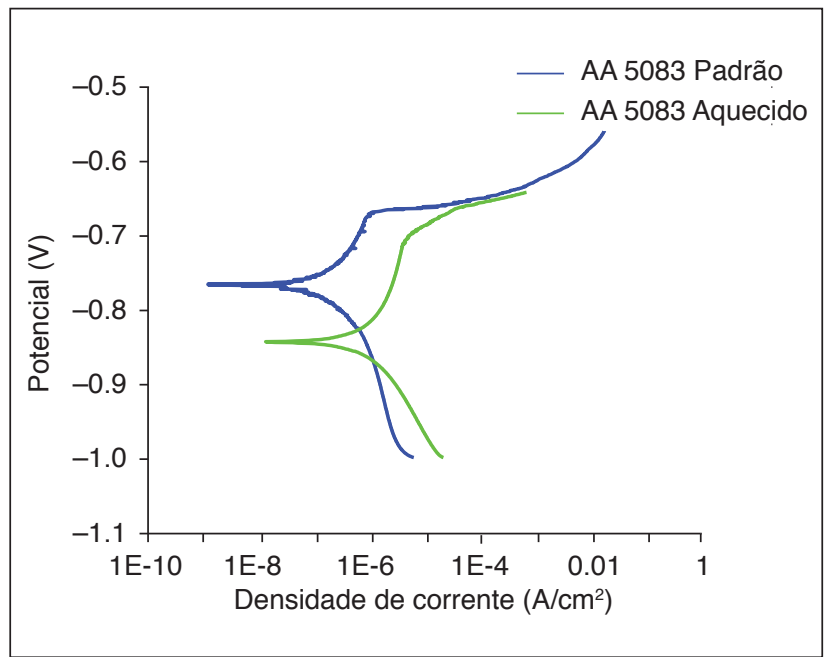

Figura 3: Curvas de polarização das amostras de liga AA5083 padrão e aquecida.
A diminuição da resistência à corrosão da liga AA 5083 aquecida pode ser explicada pela presença dos precipitados intermetálicos de $\mathrm{Al}_{2} \mathrm{Mg}_{3}$, como pode ser visto nas imagens obtidas por microscopia óptica do ensaio de imersão. Segundo alguns autores $^{16}$, a liga AA5083 tem propensão à corrosão devido à presença de duas fases intermetálicas, a primeira contendo $\mathrm{Al}, \mathrm{Mn}, \mathrm{Cr}$ e Fe e a segunda $\mathrm{Al}$, Si e Mg. A fase $\mathrm{Al}$ (Mn, Cr, Fe) apresenta caráter catódico, pois uma reação de redução do oxigênio $\left(\mathrm{O}_{2}+2 \mathrm{H}_{2} \mathrm{O}+4 \mathrm{e}-\rightarrow 4 \mathrm{OH}-\right)$ ocorre sobre esses precipitados, produzindo aumento do $\mathrm{pH}$ da solução, fazendo com que a matriz em torno do precipitado se dissolva, ocorrendo intenso ataque no material, causando aumento de pites. A presença desses precipitados repercute diretamente no comportamento geral da liga AA5083 em solução de $\mathrm{NaCl}$, causando, assim, maior corrosão localizada; dependendo de sua densidade, muda sua resposta eletroquímica $^{17,18}$. Em outro trabalho ${ }^{15}$, os autores mostraram os valores do potencial de corrosão do alumínio (99,9\%), que é de $-0,85 \mathrm{~V}$ (xSCE), e das fases intermetálicas, Al2Mg3 e Al6Mn, que têm os potenciais de corrosão de $-1,16 \mathrm{~V}$ e - $-0,91 \mathrm{~V}$ (xSCE), respectivamente, indicando o caráter mais catódico para as fases intermetálicas, principalmente da fase $\beta$, presente na liga AA5083, mencionada anteriormente. Como mostrado, também, por Buchheit et al. ${ }^{19}$, o potencial da fase $\beta$ exerce papel catódico no material em comparação com sua matriz, fazendo com que o excesso dessa fase no alumínio cause um comportamento menos resistente à corrosão em comparação com a liga padrão.

\section{Análise Metalográfica das Amostras Pelos Ensaios de Imersão}

\section{Microscopia óptica - Imersão em 42 dias}

As amostras de AA5083 ficaram imersas em água do mar durante 42 dias e, ao final do processo, fez-se observação da degradação do material em meio salino. A Fig. 4 apresenta as amostras antes do teste de imersão.

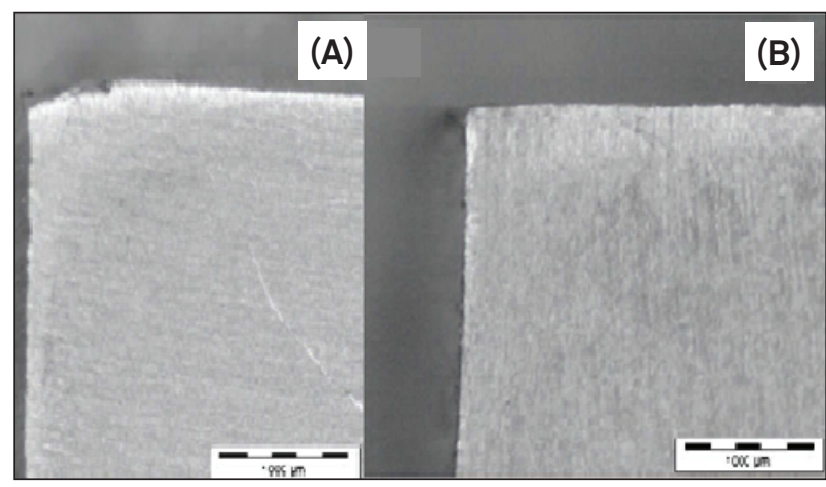

Figura 4: Amostras antes do teste de imersão em 42 dias. Ampliação de 15X padrão (A) e aquecida (B).

Realizou-se a comparação do alumínio aquecido e padrão antes e após o ensaio de imersão. A análise foi executada por microscopia óptica. A Fig. 5 mostra a análise visual da superfície 
do material, no qual pode ser vista a maior corrosão da peça aquecida em comparação com o padrão após imersão.

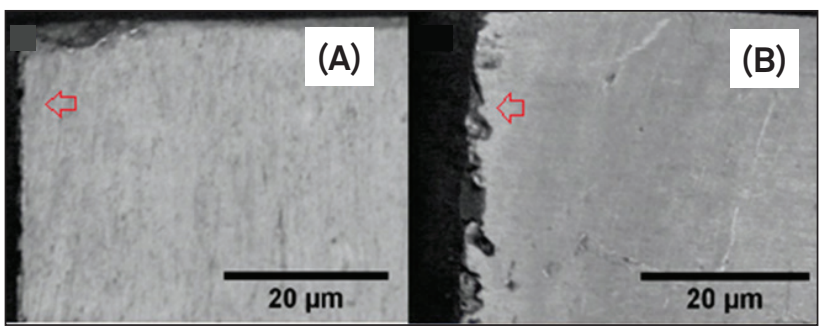

Figura 5: Imagens da superfície das amostras após imersão. Amplitude de 15X padrão (A) e aquecida (B).

As setas vermelhas indicam as bordas nas quais foi realizada a análise microscópica (Figs. 6 e 7). Selecionaram-se essas regiões pois pode ser observado onde ocorreu maior incidência de ataque corrosivo. As amostras padrão apresentaram menor corrosão em sua superfície, apresentando menores quantidades de pites pequenos espalhados em suas bordas. No alumínio aquecido, a corrosão foi maior e mais evidente, apresentando maior quantidade de pites em suas bordas, maiores e mais agrupados. Esses pites são característicos de materiais passiváveis, como descrito anteriormente.

A análise metalográfica da amostra padrão mostrou que a liga de alumínio comum não apresenta nenhum tipo de corrosão em sua microestrutura, conforme pode ser visto na Fig. 6. Observouse, somente, o contorno de grãos e alguns pontos escuros dos precipitados de fase $\beta$. A liga AA5083 padrão imersa por 42 dias não sofreu degradação em sua microestrutura pela da água do mar.

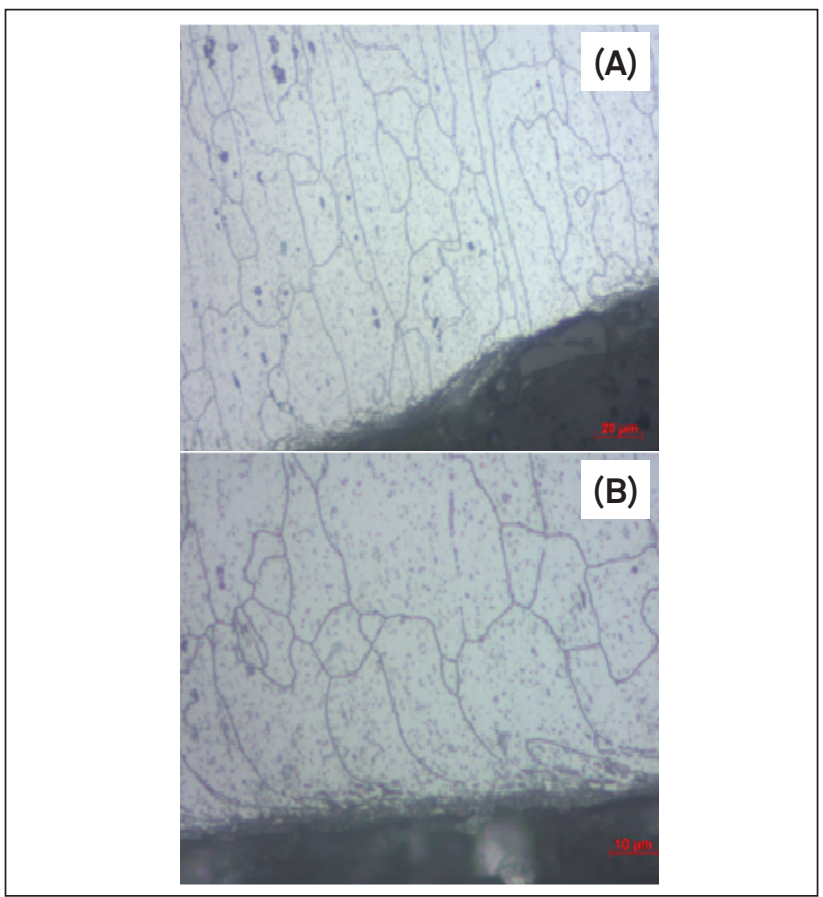

Figura 6: Microestruturas da liga AA5083 padrão. Aproximação de $500 X(A)$ e 1.000X (B), mostrando que não há corrosão em sua estrutura.
A Fig. 7 apresenta a microestrutura da liga AA5083 aquecida. Com a revelação dos grãos, a precipitação da fase $\beta\left(\mathrm{Al}_{3} \mathrm{Mg}_{2}\right)$, em vermelho, ficou evidenciada devido ao grande número de partículas de segunda fase nos contornos de grão. As bordas apresentaram princípio de corrosão intergranular, mostrado pelas setas pretas, devido ao tempo de imersão em água salgada. Ao longo da peça inteira, houve maior degradação de suas bordas com início de corrosão intergranular.

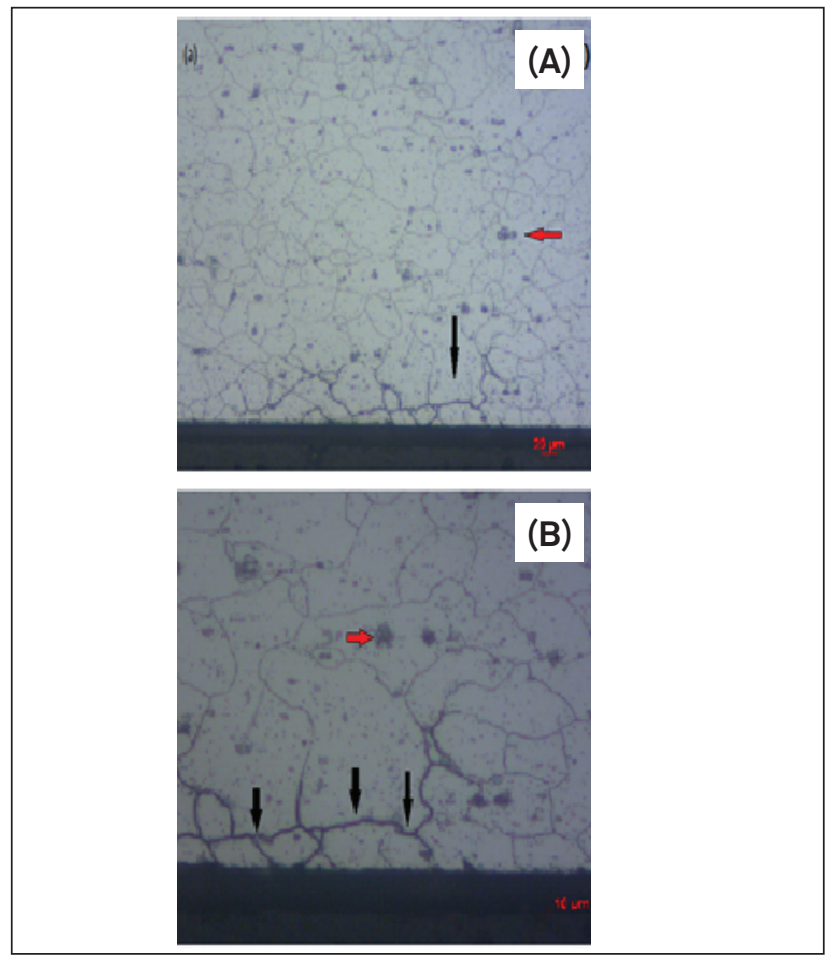

Figura 7: Microestrutura da liga AA 5083 aquecida. Aproximação de $500 X(A)$ e $1.000 X(B)$.

Segundo alguns autores ${ }^{20,21}$, a região do ataque aumenta significativamente conforme o espaçamento dos precipitados for menor ou igual a $45 \mu \mathrm{m}$, sendo que a continuidade e o espaçamento entre os grãos podem afetar a susceptibilidade da liga para corrosão intergranular. $\mathrm{O}$ tamanho dos precipitados da fase $\beta$ pode variar de 50 a $190 \mathrm{~nm}$ de largura e de 100 a $1.000 \mathrm{~nm}$ de comprimento. A morfologia da fase é ditada por diversos fatores, entre eles a temperatura, o tempo de exposição térmica e as condições metalúrgicas do material.

Após a revelação da microestrutura, ficou mais evidente a precipitação da fase $\beta\left(\mathrm{Al}_{3} \mathrm{Mg}_{2}\right)$ nos contornos de grão e foi possível evidenciar o início da corrosão do material aquecido, mostrando, assim, que, após 42 dias de imersão, as amostras começaram a apresentar início de corrosão intergranular.

\section{Microscopia óptica - Imersão em 120 dias}

As amostras de AA5083 ficaram imersas em água do mar durante 120 dias. Ao final do processo, fez-se observação da degradação da superfície do material em meio salino. A Fig. 8 
apresenta a imagem da superfície da amostra antes do teste de imersão. Observou-se a superfície uniforme das amostras padrão, contendo somente riscos do lixamento, enquanto a Fig. 9 apresenta a superfície do material após imersão em meio salino por 120 dias, na qual pode ser observada a degradação da superfície da liga de alumínio AA5083, tanto como recebida (Fig. 9a) quanto aquecida (Fig. 9b), na qual os pites são mais visíveis (setas vermelhas).

As setas vermelhas (Fig. 9) indicam a região na qual a amostra foi seccionada e a análise microscópica realizada, como mostram as Figs. 10 e 11. Essas regiões indicadas foram selecionadas pois pode ser observado onde ocorreu maior incidência de pites.

As amostras como recebidas apresentaram tanto degradação branda em sua borda como apresentaram indícios de corrosão localizada das bordas para o centro, formando pequenos pites de corrosão na superfície. No material que passou pelo processo de aquecimento (Fig. 9b), pode-se observar que houve degradação mais agressiva nas bordas, além da presença de pites, maiores e mais profundos (setas vermelhas). Ficou, ainda, evidenciado que, durante o período imerso de 120 dias, a liga AA5083 padrão começou a ter propagação de corrosão intergranular (setas pretas) por meio dos pites (setas vermelhas) no material, como visto na Fig. 10.

Nas amostras aquecidas, verificou-se degradação maior e mais profunda, sendo que a microestrutura apresentou maior área de corrosão intergranular, tanto na borda da amostra quanto no interior da superfície analisada. A Fig. 11 mostra o sentido da corrosão intergranular evidenciado pela seta preta.

A alta concentração de Mg no alumínio 5083 resulta na sua propensão à corrosão por pites, pois gera a formação da fase $\beta$ $\left(\mathrm{Al}_{2} \mathrm{Mg}_{3}\right)$ no material, fazendo com que haja maior corrosão nas

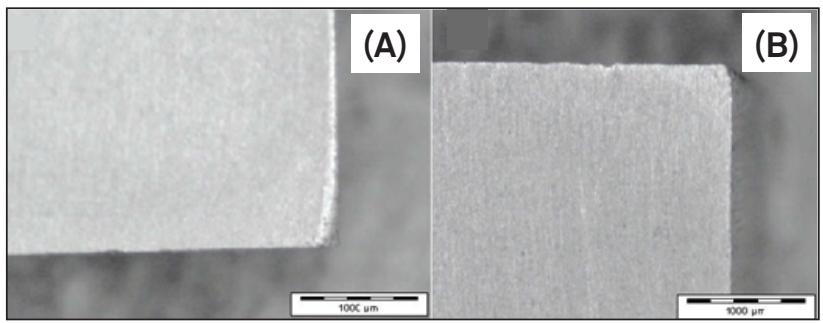

Figura 8: Imagem das amostras antes do teste de imersão em 120 dias. Ampliação de 15X padrão $(A)$ e aquecida (B).

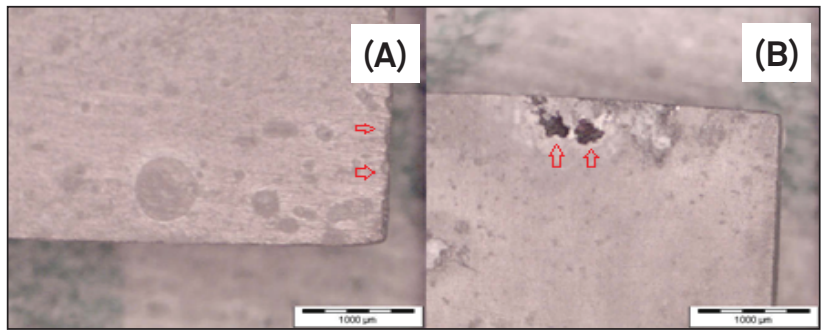

Figura 9: Imagens da superfície das amostras da liga de alumínio 5083 após a imersão em meio salino. Ampliação de 15X como recebida $(\mathrm{B})$ e pré-aquecida $(\mathrm{B})$. peças aquecidas. Embora a taxa de corrosão desse tipo de liga seja lenta em ambientes contendo cloreto, a resistência à corrosão por pites depende de sua pureza ${ }^{22}$.

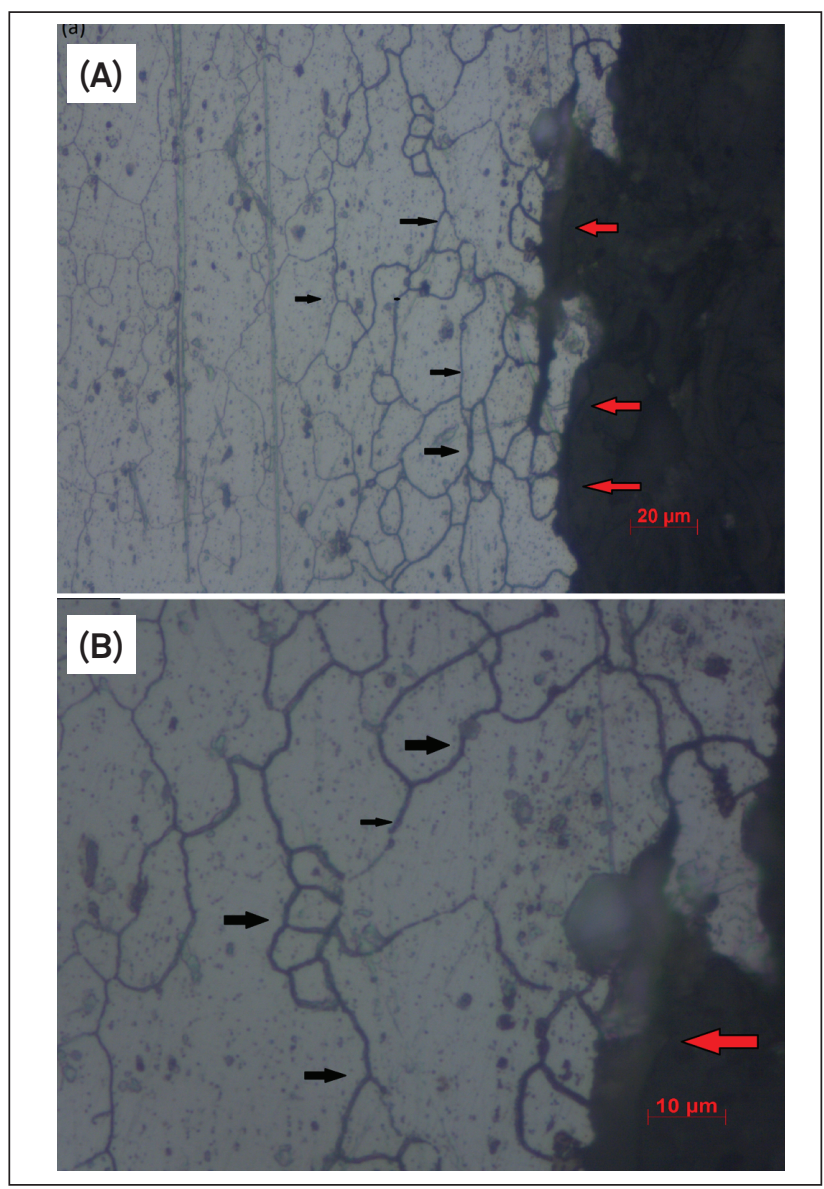

Figura 10: Microestruturas da liga AA 5083 padrão com aproximação de $500 X(A)$ e 1.000X (B), evidenciando a presença de corrosão intergranular e de pites.
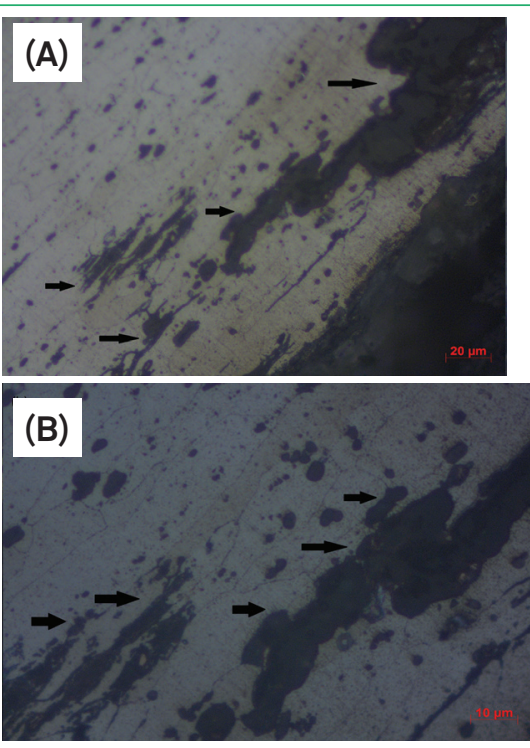

Figura 11: Microestruturas da liga AA 5083 aquecida com aproximação de $500 X(A)$ e 1.000X (B), evidenciando a presença e a direção de corrosão intergranular. 


\section{Microdureza}

Verificou-se a dureza das amostras do material aquecido e comum imersas em água do mar, a qual foi comparada com a encontrada em amostras aquecidas e padrão que não foram expostas ao ensaio de imersão. Na Tabela 3 são mostrados os valores obtidos por meio do teste de microdureza, realizando a comparação entre elas.

Tabela 3: Comparação da dureza HV (hardness Vickers) do AA 5083.

\begin{tabular}{|c|c|c|c|}
\hline $\begin{array}{c}\text { Amostras } \\
\text { imergidas }\end{array}$ & Dureza HV & $\begin{array}{c}\text { Amostras não } \\
\text { imergidas }\end{array}$ & Dureza HV \\
\hline $\begin{array}{c}\text { AA5083 } \\
\text { aquecida 1 }\end{array}$ & 112,0 & $\begin{array}{c}\text { AA5083 } \\
\text { aquecida }\end{array}$ & 116,86 \\
\hline $\begin{array}{c}\text { AA5083 } \\
\text { aquecida 2 }\end{array}$ & 113,5 & & \\
\hline $\begin{array}{c}\text { AA5083 } \\
\text { padrão 1 }\end{array}$ & 86,7 & $\begin{array}{c}\text { AA5083 } \\
\text { padrão }\end{array}$ & \\
\hline AA5083 & 84,6 & 84 \\
\hline padrão 2 & 84,6 & \\
\hline
\end{tabular}

A amostra padrão apresentou dureza entre 80 e $90 \mathrm{HV}$, enquanto a liga de alumínio aquecida apresentou maior dureza antes e depois do teste de imersão. As amostras aquecidas apresentaram durezas entre 110 e $120 \mathrm{HV}$ devido à camada de óxido formada durante o ensaio. Segundo alguns autores ${ }^{23,24}$, a liga de alumínio aquecida à temperatura de $250^{\circ} \mathrm{C}$ apresenta aumento de dureza superficial chamado pico de envelhecimento, porém, a taxa de dureza do material cairá proporcionalmente se deixado por tempo prolongado em altas temperaturas. Esse aumento na dureza da liga é devido à formação da fase intermetálica mencionada anteriormente e citada por diversos autores ${ }^{23,24}$.

\section{Análise das Massas e Taxa de Corrosão Após o Ensaio por Imersão}

Os valores de massa das amostras antes e depois da imersão por 120 dias revelaram pequeno aumento da massa referente às amostras que passaram por pré-aquecimento e por perda de massa da liga padrão na mesma ordem de valor. As taxas de corrosão, considerando-se as perdas e ganhos de massa em módulo, são apresentadas na Tabela 4.

Pode-se observar que o valor de perda de massa para a amostra padrão imersa por 120 dias foi maior $(8,5 \mathrm{mg})$ que aquela imersa durante 42 dias (5,9 mg), e para a amostra aquecida ocorreu o inverso, em 120 dias de imersão, a perda de massa foi menor
$(4,7 \mathrm{mg})$ que a amostra aquecida imersa durante 42 dias (12,4 mg). Porém, a taxa de corrosão para a amostra padrão imersa durante 42 dias foi 2,3 vezes maior $(0,046 \mathrm{~mm} / \mathrm{ano})$ que a taxa do padrão imerso durante 120 dias $(0,02 \mathrm{~mm} / \mathrm{ano})$.

O mesmo comportamento ocorre para as amostras aquecidas, a taxa de corrosão para a amostra aquecida imersa durante 42 dias foi 7,5 vezes maior $(0,098 \mathrm{~mm} / \mathrm{ano})$ que a taxa da amostra imersa durante 120 dias $(0,013 \mathrm{~mm} / \mathrm{ano})$. Esse fato sugere que tanto para a amostra padrão como para a liga aquecida, o maior tempo de imersão (120 dias) em solução de $\mathrm{NaCl}$ favoreceu a maior resistência à corrosão das ligas, pois, como a solução salina era aerada, provavelmente ocorreu a formação de uma camada de óxido sobre as ligas, produzindo maior resistência à corrosão do material. Aballe et al. ${ }^{17}$ inferiram que amostras imersas em solução salina a partir de 15 dias produz aumento na camada passiva domaterialegerafasesintermetálicas devidoàlonga prolongaçãodo material em meio de cloretos.

Em contrapartida, o efeito da diminuição da resistência à corrosão nas amostras aquecidas foi bem maior que o da amostra padrão, pois a resistência à corrosão diminuiu 7,5 vezes quando o tempo de imersão aumentou para 120 dias. Essa explicação é coerente com os resultados obtidos pelas curvas de polarização, que mostraram maior região passiva para as amostras aquecidas, indicando a formação de uma camada de óxido mais espessa.

\section{CONCLUSÕES}

Neste trabalho, o estudo do efeito do aquecimento da liga de alumínio AA5083 na resistência à corrosão em meio salino foi realizado, evidenciando que a exposição do material na temperatura de $180^{\circ} \mathrm{C}$ em $72 \mathrm{~h}$ gerou menor resistência à corrosão, evidenciando a precipitação da fase $\beta\left(\mathrm{Al}_{3} \mathrm{Mg}_{2}\right)$ e a sensitização da liga AA5083.

Nas curvas de $O C P$, observou-se o caráter mais nobre para a liga padrão em relação à aquecida e, nas curvas de polarização, obteve-se densidade de corrente de corrosão cinco vezes maior, indicando que a resistência à corrosão diminuiu cinco vezes para a liga aquecida do que para a liga padrão $\left(1,6 \times 10-8 \mathrm{~A} / \mathrm{cm}^{2}\right)$. No entanto, maior região de camada de óxido passiva foi observada nas curvas de polarização da amostra aquecida, indicando uma camada mais espessa, que produz maior resistência à corrosão da liga quando imersa em meio salino por 120 dias, como mostrado nos resultados de taxa de corrosão obtidos pelo ensaio de imersão.

Tabela 4: Valores de medidas de massa e taxa de corrosão das amostras da liga 5083 aquecidas e como recebidas após ensaio de imersão em água do mar.

\begin{tabular}{c|c|c|c|c|c|}
\hline Dias de imersão & Amostras & Massas iniciais $\mathbf{( g )}$ & Massas finais $(\mathbf{g})$ & Perda de massa $(\mathbf{m g})$ & Taxa de corrosão (mmlano) \\
\hline \multirow{2}{*}{120} & Padrão & 1,476 & 1,461 & 8,5 & 0,020 \\
& Aquecida & 1,117 & 1,100 & 4,7 & 0,013 \\
\multirow{2}{*}{42} & Padrão & 1,549 & 1,530 & 5,9 & 0,046 \\
& Aquecida & 1,207 & 1,193 & 124 & 0,098 \\
\hline
\end{tabular}


Os resultados de microdureza apresentaram valores de dureza $30 \%$ maior para as ligas aquecidas do que a padrão (80-90 HV). Esse efeito foi devido à presença da fase $\beta(\mathrm{Al} 3 \mathrm{Mg} 2)$ nos contornos de grão, evidenciada por meio da análise morfológica por microscopia óptica após ensaios de imersão salina, nos quais as amostras aquecidas apresentaram maior precipitação da fase $\beta$ $\left(\mathrm{Al}_{3} \mathrm{Mg}_{2}\right)$ na rede contínua do contorno de grão do que a amostra padrão.

Adicionalmente, depois do período de imersão de 42 e 120 dias, as macrografias e micrografias das amostras mostraram a presença de corrosão intergranular e de pites, sendo maior a incidência nas amostras da liga aquecida.

\section{REFERÊNCIAS}

1. Associação Brasileira do Alumínio. Guia técnico do alumínio tratamento térmico. São Paulo: Abal; 2003.

2. Zangrandi A. Alumínio e suas ligas: fundamentos metalúrgicos e tecnológicos. Lorena: Instituto Santa Teresa; 2008.

3. Pereira, JMMV. Estudo das ligas de alumínio aplicadas em construção naval nomeadamente na resistência à corrosão em estruturas navais soldadas [dissertação]. Lisboa: Univessidade Nova de Lisboa, Lisboa; 2010

4. Goswami R, McLean VA, Soanos G, Pao OS, Holtz RL. Precipitation behavior of the $\beta$ phase in Al-5083. Mater Sci Eng A. 2010;527(4-5)1089-95. https://doi.org/20.1016/i.msea.10.007

5. Martins NEC. Soldadura das ligas de alumínio de construção naval [dissertação]. Lisboa: Universidade Nova de Lisboa; 2008.

6. Magarola SC, Beltran J. Manual del alumínio. 11a ed. Barcelona: Editorial Revertê; 1959

7. Crane CB, Gangloff RP. Stress corrosion cracking of Al-Mg Alloy 5083 sensitized at low temperature. Corrosion. 2015;72(2)22141. https://doi.org/10.5006/1766

8. Sartori A, Silva B. Influência do tempo de exposição e temperaturas elevadas na microestrutura da liga AA5083. Anais do III Congresso Internacional do Alumínio; 2007 data São Paulo; Editora; 2007

9. Sartori A, Veiga J. Determinação da susceptibilidade à corrosão intergranular, para ligas Al-Mg $(5 X X X)$ com mais de $3 \%$ de $\mathrm{Mg}$, através da perda de massa por unidade de área. Pindamonhangaba; Editora; 2005.

10. Ramanathan LV. Corrosão e seu controle. São Paulo: Hemus; c1997.
11. Nunez LP. Fundamentos de resistência a corrosão. Rio de Janeiro: Interciência; 2007.

12. Savonov GS. Implantação iônica por imersão em plasma em materiais metálicos leves [tese]. São José dos Campos: Instituto Tecnológico de Aeronáutica; 2011.

13. Callister W. Corrosão e degradação dos materiais. In: Callister W. Fundamentos da ciência e engenharia de materiais: uma abordagem integrada. 2a ed. Rio de Janeiro: LTC; 2006.

14. Wolynec S. Técnicas eletroquímicas em corrosão. São Paulo: Edusp; 2003

15. Birbilis N, Buchheit RG. Electrochemical characteristics of intermetallic phases in aluminum alloys. J Electrochem Soc. 2005;152(4)B140-51. https://doi.org/10.1149/1.1869984

16. Chen S, Li GM, Chang WS, Chen XQ. The research of electrochemical behavior of alloy AA5083 in $3.5 \% \mathrm{NaCl}$ solution. Adv Mater Res. 2013;676(1)80-4. https://doi.org/10.4028/www. scientific.net/AMR.676.80

17. Aballe A, Bethencourt M, Botana J, Cano MJ. Localized alkaline corrosion of alloy AA5083 in neutral $3.5 \% \mathrm{NaCl}$ solution Corros Sci. 2001;43(9)1657-74. https://doi.org/10.1016/S0010938X(00)00166-9

18. Aballe A, Bhetencourt M, Botana J, Marcos-Bárcena M, Osuna $\mathrm{RM}$. Influence of the $\mathrm{Al}(\mathrm{Mn}, \mathrm{Fe}, \mathrm{Cr})$ precipitates distribution of the electrochemical response of AA5083 alloy in $\mathrm{NaCl}$ solution. Rev Metal Madrid. 2002;38(2)100-7. https://doi.org/10.3989/ revmetalm.2002.v38.i2.389

19. Buchheit RG, Borger RK, Carroll MC, Leard RM, Paglia C Searles JL. The electrochemistry of intermetallic particles and localized corrosion in Al alloys. JOM. 2001; 53(7)29-33. https:// doi.org/10.1007/s11837-001-0084-x

20. Jain S, Lim MLC, Hudson JL, Sully JR. Spreading of intergranular corrosion on the surface of sensitized Al-4.4 Mg alloys: a general finding. Corros Sci. 2012;59(1)136-47. https://doi.org/10.1016/i. corsci.2012.02.018

21. Jain S, Hudson JL, Scully JR. Effects of constituent particles and sensitization on surface spreading of intergranular corrosion on a sensitized AA5083 alloy. Electrochim Acta. 2013;108:253-64. https://doi.org/10.1016/i.electacta.2013.06.036

22. Ezuber H, El-Houd A, El-Shawesh F. A study on the corrosion behavior of aluminum alloys in seawater. Mater Des. 2008;29(4)801-5. https://doi.org/10.1016/j.matdes.2007.01.021

23. Oguocha INA, Adigun OJ, Yannacopoulos S. Effect of sensitization heat treatment on properties of Al-Mg alloy AA5083-H116. J Mater Sci. 2008;43(12)4208-14. https://doi.org//10.1007/s10853008-2606-1

24. Wei W. Study of sensitization in AA5083 aluminium alloy [dissertação]. Manchester: Universidade de Manchester; 2017. 